\title{
Study on TMT Heterogeneity's Effects on Corporate Performance from the Perspective of Leadership Structure
}

\author{
Jian He, Li Li, Weining Li \\ School of Business Administration, South China University of Technology, Guangzhou, China \\ Email: jxschej@163.com
}

Received 4 January 2016; accepted 23 January 2016; published 26 January 2016

Copyright (C) 2016 by authors and Scientific Research Publishing Inc.

This work is licensed under the Creative Commons Attribution International License (CC BY). http://creativecommons.org/licenses/by/4.0/

c) (i) Open Access

\begin{abstract}
Based on Upper Echelons theory, this article makes use of a sample of 130 companies that experienced CEO succession due to performance decline to investigate whether the TMT heterogeneity impact on corporate performance and how the leadership structure of corporation moderates the relationship between them. It is shown that TMT age heterogeneity has a $U$-shaped relationship with corporate performance; TMT tenure heterogeneity and TMT educational levels heterogeneity have inverted U-shaped relationship with corporate performance; while the leadership structure of corporation has a moderating effect on the relationship between TMT age heterogeneity, TMT tenure heterogeneity and corporate performance. The findings of this study would be helpful to cultivate and construct the entrepreneurial TMT, and to design corporate leadership structure.
\end{abstract}

\section{Keywords}

CEO, TMT Heterogeneity, Leadership Structure, Corporate Performance

\section{Introduction}

Upper Echelons (UE) [1] theory holds that demographic characteristics of top management team (TMT) effectively reflect TMT members' traits, including cognitive basis, value principle and insights which make effects on TMT members' knowledge of business environment and strategic decisions as well as corporate performance ultimately. Present literature pays more attention and makes research on TMT heterogeneity's effects on corporate strategy and performance. However, conclusion by different researchers comes to difference. Scholars have pointed that situationalization study of TMT heterogeneity should be focused on [2]. While most researchers took external environmental characteristics as moderators or mediators to reveal mechanisms in TMT strategic 
decisions, some researchers now make deep study on how internal corporate characteristics, such as equity structure, team atmosphere, communication frequency, affect TMT strategic decision. However, there is rare study from the perspective of corporate internal governance mechanism.

As the core of corporate internal governance, leadership structure affects TMT freedom and innovation desire, which leads to different strategic decisions that influences corporate performance. Present literature shows that most studies focus on leadership structure's effects on corporate performance based on principal-agent theory and resource-based view [3] [4], while CEO (Chief Executive Officer) or TMT's individual characteristics' influence under different leadership structures has been rarely stressed, which is the literature limitation and also the focus of this study. Therefore, introducing leadership structure as a variable to enhance situational characteristics in TMT heterogeneity study, and exploring leadership structure's effects on TMT strategic decisions is of importance to explain the situation in which TMT heterogeneity improves performance.

As China comes into the transitional period of economic growth and structural adjustment, Chinese enterprises face the continuous decline in performance. The enterprises with performance decline often make strategic transformation by replacing CEO and restructuring TMT, in order to reverse the non-performing situation. As with CEO succession, leadership structure will be adjusted. Thus, that whether the fitness between new CEO and TMT makes effects on strategic decision and implementation in different leadership structures or not needs a further empirical research. This study collects a sample of the companies listed on Shanghai and Shenzhen exchanges that have replaced CEO after continuous decline in performance, based on Upper Echelons and corporate governance theory. The breakthroughs of this study are as follows. First, this study holds that TMT heterogeneity has non-linear relationship with corporate performance while most studies focus on the linear impacts. Second, based on Upper Echelons and corporate governance theory, this study introduces leadership structure as a situational variable to reveal TMT heterogeneity's effect mechanism on corporate performance in a more accurate way, and provides advice for TMT construction and leadership structure design.

\section{Literature Review and Research Hypothesis}

\subsection{TMT Heterogeneity and Corporate Performance in Performance-Declining Enterprises}

TMT heterogeneity refers to heterogeneity not only in the demographic diversity, such as races, age, tenure, education, but also in the cognition and values among TMT members [5]. Julian et al. [6] found that TMT heterogeneity affected corporate openness and supplied diverse information for team decision which contributed to improve decision quality and performance, when they researched joint ventures in Thailand. Yang, L. and Wang [7] pointed that TMT heterogeneity in age, gender and work experience lead enterprises to position the strategies that help to improve performance. However, Huang Y. and Yang N. D. found that TMT average age and age heterogeneity had negative relationship with corporate performance and equity centralization made negative moderating effect on the relationship, when they did empirical research on 153 companies listed on Shanghai exchange. Fan M. and Jiao L. B. [8] also found that TMT age heterogeneity and tenure heterogeneity were negatively related with corporate performance since they took the data in 2010 from Shanghai and Shenzhen GEM (Growth Enterprise Market) exchanges. Velinov et al. [9] even found no relationship between TMT age, tenure heterogeneity and corporate performance, as they studied on 37 IPO listed enterprises during 2008 to 2012. Since present researches show difference and even contradiction in the relationship between TMT heterogeneity and corporate performance, we propose that it is limited to say TMT heterogeneity has linear relationship with corporate performance, and the non-linear relationship and effects of leadership structure have been neglected.

The strategy in performance-declining enterprises can not be adapted to the business environment they confront, so TMT need to adjust strategy to reverse the non-performing situation. TMT heterogeneity reflects TMT members' competence in communication and cooperation as well as capability of collection and filtering to market information and data, which affect strategic quality. If TMT heterogeneity is low, members have similar experience and values, so they have similar manners and strategic decision to keep less conflict and better communication but lack insights and diverse viewpoints in a whole [10]. And the team is inclined to keep the original strategy and hard to motivate innovation, which is easy to miss the opportunity to reverse the non-performing situation. If TMT heterogeneity reaches a temperate level, members share intelligence, expertise, capital and so on, which keep decision innovation and equality to improve corporate performance. If TMT heterogeneity goes beyond the limit, motivation to innovate disappear while emotional conflicts increase and communica- 
tion becomes less, leading to low efficiency and equality in decision [11]. Since China is in a transitional period with social structure and institutional environment increasingly changing, lack of coordination and regulation will hinder communication and make decision failure, and lead to performance decline ultimately. Thus, this study proposes the first hypothesis:

Hypothesis 1: with the new CEO succession in performance-declining corporate, TMT heterogeneity (age/ tenure/education) has inverted U-shaped relationship with corporate performance.

\subsection{Leadership Structure Moderates the Relationship between TMT Heterogeneity and Corporate Performance in Performance-Declining Enterprises}

As corporate governance mechanism, leadership structure means that whether chair of the board and CEO position are taken upon one person or different persons. It reflects the balance between independence and supervisorship of the board, and innovation freedom of TMT [12], which affects TMT innovation behavior and strategic decision that influences corporate performance ultimately. Heretofore there rarely has been common conclusion about the effect of leadership structure. Principal-agent theory proposes that the chair-CEO duality will weaken supervision and control of the board and increase governance risk. Meanwhile, such a combination promotes the interaction and information communication between TMT and the board, and prevents conflict [13]. Management autonomy theory and decision theory hold that corporate performance has much closer relationship with TMT characteristics under chair-CEO duality. On the other hand, the separation of chair and CEO will constrain TMT's innovation and autonomy, and weaken TMT's effects on corporate performance, even though the separation guarantees supervision and control of the board and avoid TMT opportunistic behavior.

As to the performance-declining enterprises with chair-CEO duality, TMT heterogeneity's effects on corporate performance could be more significant. If TMT heterogeneity is low, chair-CEO duality will make the board out of control of CEO who might take opportunities to pay more attention to individual benefit but less to long-term corporate development, which lead to lower performance. If TMT heterogeneity reach to a temperate level, there will be a balance between TMT innovation freedom and board independence, as chair-CEO duality gives CEO more power to accelerate decision speed that adjusts performance-declining enterprises to environment. Meanwhile, chair-CEO duality improves coordination between the board and management to obtain external resource and make full use of social capital like social network and political status in the board, so that strategic decision can be implemented smoothly to improve performance. If TMT heterogeneity is high, chairCEO duality will intensify TMT conflicts as lack of supervision mechanism, which make performance worse.

As to the performance-declining enterprises with separation of chair and CEO, TMT heterogeneity has less significant effects on corporate performance. Separation of chair and CEO takes more effective supervision and control on CEO and TMT, and enhances independence of the board to protect corporate from risk, which but also misses chance to develop easily. Therefore, no matter TMT heterogeneity is high or low, performance-declining enterprises with separation of chair and CEO are inclined to take conservative strategies to keep stability. Thus, this study proposes the second hypothesis:

Hypothesis 2: with the new CEO succession in performance-declining corporate, leadership structure moderates the relationship between TMT heterogeneity (age/tenure/education) and corporate performance. Namely, the higher leadership structure is, the more significantly TMT heterogeneity affects corporate performance in the inverted U shape.

\section{Methodology}

\subsection{Sample Selection}

This study takes China performance-declining enterprises as research subjects, and measures the subjects according to 'absolutely declining performance in succeeding 3 years at least' proposed by Ran M.. If ROAci (Corporate Return on Assets) in three years before CEO succession minus ROAIi (Industry Average Return on Assets) is negative value and the absolute value consistently increase in this three years, we define the corporate as performance-declining corporate. As to TMT definition, there is no common standard. CHO proposed that TMT includes vice-president and the above titles [14]. Sun H. F. et al. hold that TMT includes chair of the board, general manager, function directors and managers who participate decisions on the top. According to China listed corporation regulation, we select vice-president, deputy general manager, chief accountant, chief engineer 
and other top managers as TMT members.

The sample enterprises selected in this study are fit in following standards: 1) the corporates listed on Shanghai and Shenzhen exchanges with three years succeeding performance decline, and experiencing CEO succession during 2009 to 2011 but staying CEO unchanged in the next three years; 2) the corporates that succeed CEO because of promotion, death, crime, term expiration or demission should be eliminated; 3) the corporates where chair-CEO state has changed during 2009-2011 should be eliminated; 4) the corporates in finance industry, ST, PT and without complete data should be eliminated. As the statistics tested in this study go through the previous three years as well as the next three years, the actual samples used spread 2006 to 2014. Finally, we assure 130 sample enterprises.

Statistics used in this study are from CSMAR database, Gildata and Corporate Financial Statement, with part of information from Sina Finance net and SPSS20.0 software for data processing.

\subsection{Variables Definition and Measurement}

Variables classification and coding rules are shown in Table 1.

\section{Results}

\subsection{Variables Descriptive Statistics and Correlation Analysis}

The results of variables descriptive statistics and correlation analysis are shown in Table 2. We can see that TMT age, tenure and education heterogeneity in the sample enterprises are high, as the values are $0.882,0.629$, 0.609. Besides, some variables have close relationships that have passed significance test. However, as influenced by other factors like sample capacity and control variables, all of the variables need to be a further analysis.

\subsection{Results of Hypothesis Test}

Considering interacting influence, we processed data in hierarchical regression models by joining control variables, independence variables, moderators and interaction items of independence variables and moderators step by step. In order to avoid multicollinearity problem, we made centralization process on independence variables

Table 1. Variables and computation methods.

\begin{tabular}{|c|c|c|c|}
\hline Type & Name & Code & Computation \\
\hline \multirow{3}{*}{ Dependent variable } & \multirow{3}{*}{ Corporate performance } & \multirow{3}{*}{$\mathrm{ROA}$} & $\mathrm{ROA}=$ net return/annual average total assets \\
\hline & & & $R O A=\left(R O A_{2}+R O A_{3}\right) / 2$ \\
\hline & & & $\begin{array}{l}\text { 2, } 3 \text { respectively refers to the second year and third year of CEO } \\
\text { succession }\end{array}$ \\
\hline \multirow{5}{*}{ Independent variable } & Age heterogeneity & На & $\mathrm{Ha}=\mathrm{TMT}$ members age standard deviation/age mean \\
\hline & Tenure heterogeneity & $\mathrm{Ht}$ & $\mathrm{Ht}=\mathrm{TMT}$ members tenure standard deviation/tenure mean \\
\hline & \multirow{3}{*}{$\begin{array}{l}\text { Educational level } \\
\text { heterogeneity }\end{array}$} & \multirow{3}{*}{$\mathrm{Hl}$} & Herfindal-Hirschman coefficient: $\quad H=1-\sum_{i}^{n} p_{i}^{2}$ \\
\hline & & & $p_{i} \quad$ refers to the proportion of $i$ type members \\
\hline & & & $\begin{array}{l}\text { TMT educational levels include special secondary or below, junior } \\
\text { college, undergraduate, master degree and doctor degree }\end{array}$ \\
\hline \multirow[t]{3}{*}{ Moderator } & Leadership structure & $\mathrm{L}$ & Dummy variable, chair-CEO duality noted as 1 , otherwise as 0 \\
\hline & Corporate age & A & The length from corporate startup to the year of CEO succession \\
\hline & Corporate size & $\mathrm{S}$ & $\begin{array}{l}\text { Natural logarithm of total assets mean value in the year before } \\
\text { CEO succession, the first and second year after CEO succession }\end{array}$ \\
\hline \multicolumn{4}{|l|}{ Control variable } \\
\hline & Capital structure & $\mathrm{D}$ & $\begin{array}{l}\text { The ratio of total liabilities to total assets in the first year } \\
\text { after CEO succession }\end{array}$ \\
\hline & Industry & IND & 14 industries noted as 13 dummy variables \\
\hline
\end{tabular}


Table 2. Correlation matrix.

\begin{tabular}{|c|c|c|c|c|c|c|c|c|c|}
\hline Variable & Mean & $\begin{array}{l}\text { Standard } \\
\text { devistion }\end{array}$ & 1 & 2 & 3 & 4 & 5 & 6 & 7 \\
\hline $1 \mathrm{ROA}$ & 0.039 & 0.310 & & & & & & & \\
\hline $2 \mathrm{~S}$ & 11.777 & 0.891 & $0.178^{*}$ & & & & & & \\
\hline $3 \mathrm{~A}$ & 12.050 & 3.962 & -0.058 & $-0.183^{*}$ & & & & & \\
\hline $4 \mathrm{D}$ & 0.631 & 0.405 & $0.333^{* * *}$ & -0.064 & $0.180^{*}$ & & & & \\
\hline $5 \mathrm{~L}$ & 0.120 & 0.330 & $0.156+$ & -0.007 & 0.078 & 0.049 & & & \\
\hline $6 \mathrm{Ha}$ & 0.882 & 0.029 & 0.113 & 0.021 & 0.001 & $0.225^{*}$ & 0.018 & & \\
\hline $7 \mathrm{Ht}$ & 0.629 & 0.174 & $0.168^{*}$ & $0.303^{* * *}$ & -0.055 & -0.059 & -0.048 & -0.102 & \\
\hline $8 \mathrm{H} 1$ & 0.609 & 0.073 & $-0.176^{*}$ & -0.119 & 0.010 & -0.051 & -0.074 & 0.139 & $-0.234^{* *}$ \\
\hline
\end{tabular}

and moderators, and computed interaction items that were then taken into regression equation. From Table 3 we can see deviation expansion coefficient of each variable in four models is below 5 , which means there is no multicollinearity problem.

Model 1 is the regression model of control variables and dependence variables; model 2 is the regression model of control variables, independence variables and dependence variables; model 3 takes centralized quadratic terms of TMT heterogeneity into the regression equation, of which the results show a positive relationship between quadratic terms of TMT heterogeneity and corporate performance with the regression coefficient 0.142 ( $p<0.1$ ), reflecting a U-shaped relationship between TMT heterogeneity and corporate performance (Figure 1). Quadratic term coefficients of tenure heterogeneity and education heterogeneity are $-0.252(\mathrm{p}<0.05),-0.190(\mathrm{p}<$ 0.05 ), reflecting an inverted U-shaped relationship between tenure, education heterogeneity and corporate performance (Figure 2 \& Figure 3). Thus, hypothesis 1 is partly supported.

In model 4 where leadership structure, interaction items of leadership structure and TMT heterogeneity, and interaction items of leadership structure and TMT heterogeneity quadratic terms were joined, F value is 6.678 ( $p<0.001$ ), and adjusted value is 0.563 that has increased, reflecting leadership structure's significant moderating effect on relationship between TMT heterogeneity and corporate performance. The regression coefficients of interaction items of age heterogeneity quadratic term, tenure heterogeneity quadratic term and leadership structure are $0.705(\mathrm{p}<0.001),-0.301(\mathrm{p}<0.1)$, which means that the higher leadership structure is, the more significant TMT age heterogeneity's U-shaped effect is (Figure 4), and the more significant TMT tenure heterogeneity's inverted U-shaped effect is (Figure 5). Thus, hypothesis 2 is partly supported.

\section{Discussion}

\subsection{Inverted U-Shaped Relationship between TMT Tenure, Education Heterogeneity and Corporate Performance}

We find that TMT tenure, education heterogeneity have inverted U-shaped relationship with corporate performance. Namely, corporate performance reaches to the best when TMT tenure and education heterogeneity are moderate. If TMT tenure and education heterogeneity is below the moderate level, organization will lack innovation and miss a lot of opportunities. But once TMT tenure and education heterogeneity go beyond the level, team cohesion and satisfaction decrease with conflicts increase. It implicates that enterprises should set appropriate recruitment and selection standards as well as tenure length, and consciously allocate and adjust TMT members in principle of moderation, to make the most optimum combination for performance improvement.

\subsection{U-Shaped Relationship between TMT Age Heterogeneity and Corporate Performance}

Findings show a U-shaped relationship between TMT age heterogeneity and corporate performance which is coordinated with research by Richard and Shelor [15] but different with our hypothesis. The reason might be age heterogeneity's special influence compared with tenure and education heterogeneity under China present institutional background and managerial situation. As coordination and cooperation are needed between functions in 
Table 3. Regression results of TMT heterogeneity, leadership structure and corporate performance.

\begin{tabular}{|c|c|c|c|c|}
\hline \multirow{2}{*}{ Variables } & \multicolumn{4}{|c|}{ Corporate Performance } \\
\hline & Model 1 & Model 2 & Model 3 & Model 4 \\
\hline Constants & -0.166 & -0.268 & -0.284 & -0.981 \\
\hline A & -0.042 & -0.051 & -0.047 & -0.027 \\
\hline $\mathrm{D}$ & $0.195^{*}$ & $0.185^{*}$ & $0.128^{+}$ & 0.096 \\
\hline S & -0.003 & -0.049 & -0.031 & 0.008 \\
\hline IND & YES & YES & YES & YES \\
\hline На & & 0.059 & 0.113 & $0.174^{*}$ \\
\hline $\mathrm{Ht}$ & & $0.134^{+}$ & -0.031 & -0.069 \\
\hline H1 & & $-0.131^{+}$ & $-0.240^{* *}$ & $-0.200^{*}$ \\
\hline $\mathrm{Ha}^{2}$ & & & $0.142^{+}$ & $0.511^{* * *}$ \\
\hline $\mathrm{Ht}^{2}$ & & & $-0.252^{*}$ & $-0.163^{+}$ \\
\hline $\mathrm{H} 1^{2}$ & & & $-0.190^{*}$ & $-0.130^{+}$ \\
\hline $\mathrm{L}$ & & & & $-0.285^{*}$ \\
\hline $\mathrm{Ha} \times \mathrm{L}$ & & & & $0.287^{* * *}$ \\
\hline $\mathrm{Ht} \times \mathrm{L}$ & & & & 0.198 \\
\hline $\mathrm{H} 1 \times \mathrm{L}$ & & & & -0.088 \\
\hline $\mathrm{Ha}^{2} \times \mathrm{L}$ & & & & $0.705^{* * *}$ \\
\hline $\mathrm{Ht}^{2} \times \mathrm{L}$ & & & & $-0.301^{+}$ \\
\hline $\mathrm{H} 1^{2} \times \mathrm{L}$ & & & & -0.028 \\
\hline Adjusted $R^{2}$ & 0.320 & 0.343 & 0.417 & 0.563 \\
\hline$\Delta R^{2}$ & -- & 0.036 & 0.077 & 0.142 \\
\hline$\Delta F$ & -- & $2.315^{+}$ & $5.632^{* *}$ & $6.934^{* * *}$ \\
\hline$F$ & $4.760^{* * *}$ & $4.515^{* * *}$ & $5.165^{* * *}$ & $6.678^{* * *}$ \\
\hline
\end{tabular}

Note: $\mathrm{N}=130,{ }^{* * *} \mathrm{p}<0.001,{ }^{* *} \mathrm{p}<0.01,{ }^{*} \mathrm{p}<0.05,{ }^{+} \mathrm{p}<0.10$, two-tailed test.

\section{Corporate Performance}

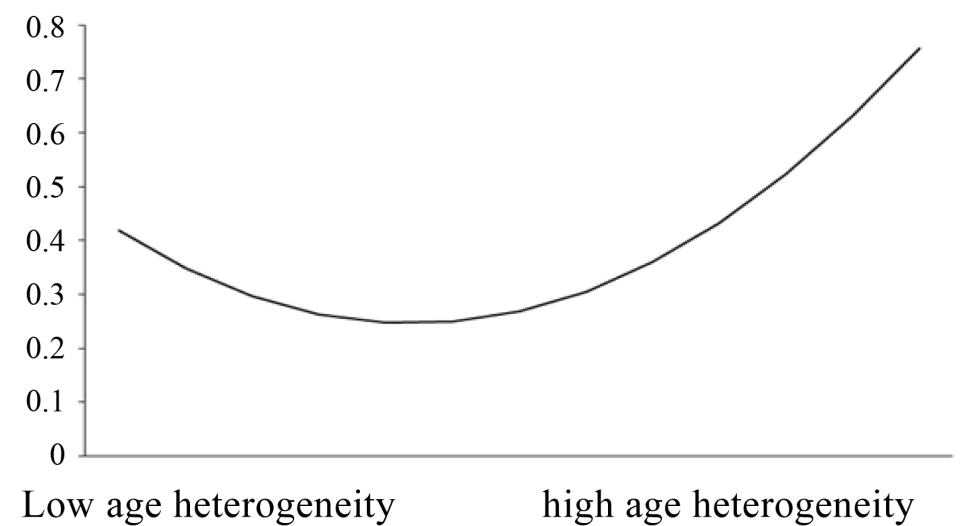

Figure 1. U-shaped relationship between TMT age heterogeneity and corporate performance. 


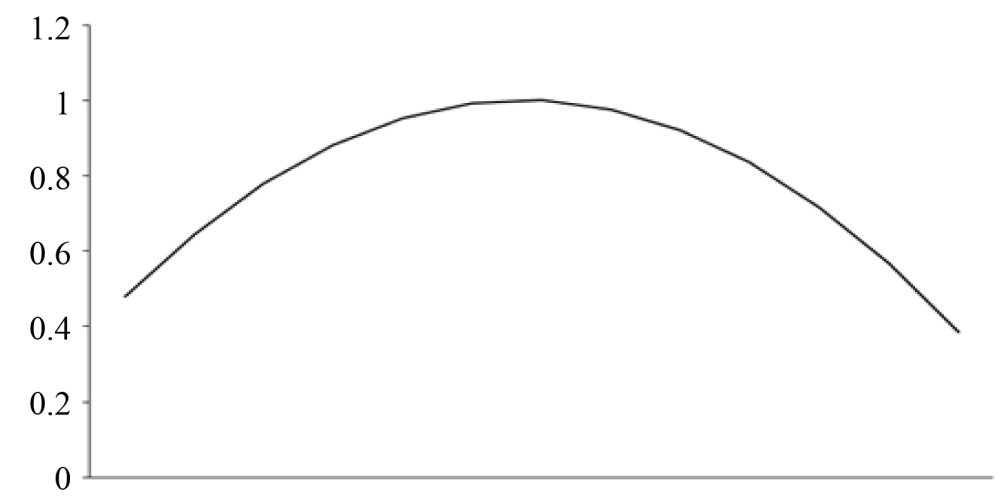

\section{Low tenure heterogeneity high tenure heterogeneity}

Figure 2. Inverted U-shaped relationship between TMT tenure heterogeneity and corporate performance.

Corporate Performance

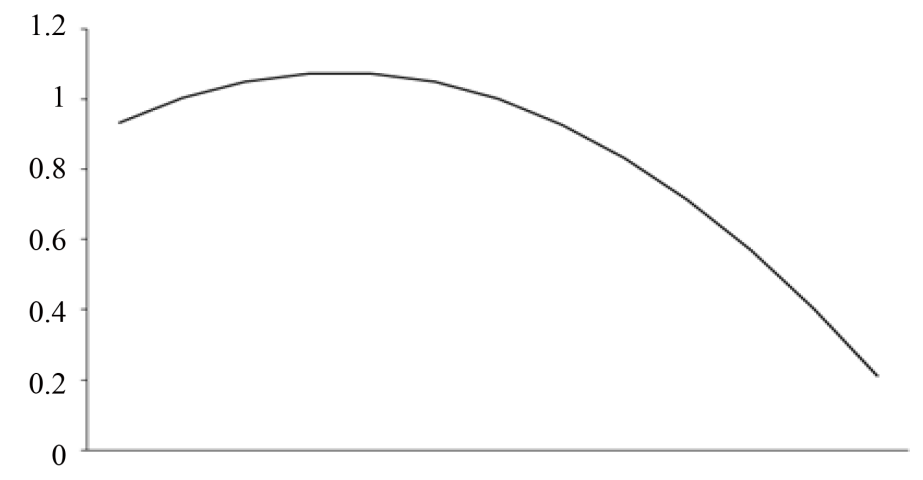

Low education heterogeneity high education heterogeneity

Figure 3. Inverted U-shaped relationship between TMT education heterogeneity and corporate performance.

Corporate Performance

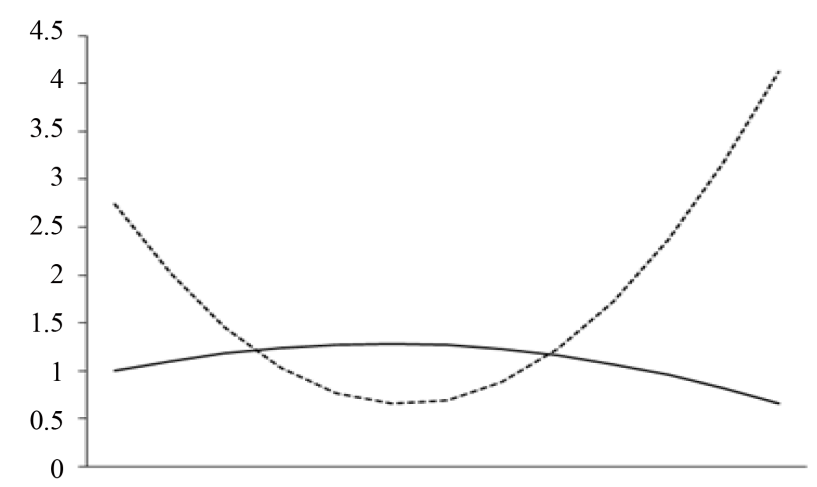

Low leadership structure

- - - High leadership structure

Low age heterogeneity

high age heterogeneity

Figure 4. Leadership structure's moderating effect on U-shaped relationship between TMT age heterogeneity and corporate performance. 
Corporate Performance

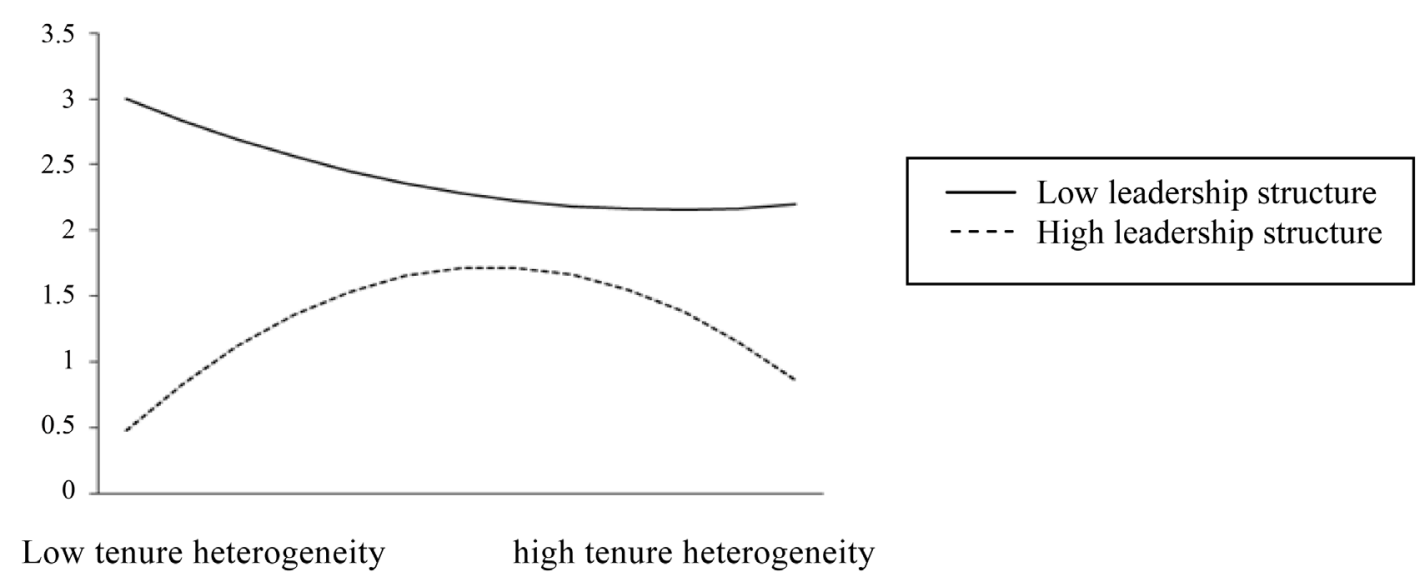

Figure 5. Leadership structure's moderating effect on inverted U-shaped relationship between TMT tenure heterogeneity and corporate performance.

performance-declining enterprises, TMT with low age heterogeneity keeps unanimous cognitive ability to reach agreement that helps to improve performance. When age heterogeneity reaches to a moderate level, corporate performance goes down, which might be caused by: on one hand, as a dominant variable to classify oneself [16], moderate age heterogeneity makes team polarized and influences corporate performance; on the other hand, heterogeneity advantages are restricted by institutional environment and collectivism. However, higher age heterogeneity contributes to obtain resources and support from social network, especially the older members do well in dealing with government and society. Meanwhile, the younger members are more innovative and adaptive to improve decision quality and corporate performance. It implicates that it's better to build a team with low age heterogeneity to keep common cognition and accelerate decision speed, or a team with high age heterogeneity to motivate innovation to improve performance.

\subsection{Leadership Structure's Moderating Effects}

From Figure 4 \& Figure 5 it can be seen that leadership structure makes significant moderating effect on the relationship between TMT age, tenure heterogeneity and corporate performance. Namely, the higher leadership structure is, the more significant TMT age heterogeneity's U-shaped effect is (Figure 4), and the more significant TMT tenure heterogeneity's inverted U-shaped effect is (Figure 5). Besides, relationship between leadership structure and corporate performance is determined by L-H fit (L-leadership structure; H-TMT heterogeneity). It implicates that management can adjust L-H fit to improve performance. In details, CEO or chair can be changed to influence interaction between CEO and the board; or enterprises keep leadership structure unchanged to avoid organizational fluctuation while adjusting TMT members to fit leadership structure and improve performance. As China corporate external governance mechanism is relatively void, enterprises should not only depend on governance effect of leadership structure, but also pay more attention to combination effect of internal governance mechanism, like management holding share, rational design of equity structure, and market-oriented personnel mechanism.

\section{Limitations and Opportunities for Future Researches}

There are still some limitations about this study: 1) TMT demographic characteristics are restraint to represent TMT members' cognitive abilities in complex environment, especially in China transitional economic environment. 2) It's difficult to analyze the complicated relationship between variables accurately because of industrial selection and data sourcing. 3) As most information of this study comes from annual statements of listed enterprises, the related data are incomplete because of disclosure regulations. Besides, share-holding, salary, reputation and individual characteristics are not taken into consideration in this study. 
Future researches could be carried on from following aspects: 1) TMT characteristic variables can be selected in a broader scale, especially psychological characteristics like power, managerial cognition. 2) More moderators or mediators can be selected. As the relationship between TMT characteristics and corporate performance is still a black box, other variables can be analyzed, like behavior integration, team process, and incentive system and so on. As to Chinese enterprises in transitional environment, relation net, social rules and trust should be taken into consideration except for technical and market factors, which will be more meaningful.

\section{Acknowledgements}

This research was supported by the National Natural Science Foundation of China (The influence of new CEO characteristics and TMT heterogeneity on performance-declining enterprises' strategic decisions and corporate performance, 71172073).

\section{References}

[1] Hambrick, D.C. and Mason, P.A. (1984) Upper Echelons: The Organization as a Reflection of Its Top Managers. Academy of Management Review, 9, 193-206.

[2] Zhang, P. (2006) A Review of TMT Heterogeneity Researches. Science and Technology Management Research, 26, 143-148.

[3] Sarkar, J., Sarkar, S. and Sen, K. (2008) Board of Directors and Opportunistic Earnings Management: Evidence from India. Journal of Accounting, Auditing \& Finance, 23, 517-551.

[4] Daily, C.M., Dalton, D.R. and Cannella, A.A. (2003) Corporate Governance: Decades of Dialogue and Data. Academy of Management Review, 28, 371-382.

[5] Finkelstein, S. and Hambrick, D.C. (1997) Review: Strategic Leadership: Top Executives and Their Effects on Organizations. Australian Journal of Management.

[6] Julian, C.C., Wachter, R.M. and Mueller, C.B. (2009) International Joint Venture Top Management Teams: Does Heterogeneity Make a Difference? Journal of Asia-Pacific Business, 10, 107-129. http://dx.doi.org/10.1080/10599230902880649

[7] Yang, L. and Wang, D. (2014) The Impacts of Top Management Team Characteristics on Entrepreneurial Strategic Orientation: The Moderating Effects of Industrial Environment and Corporate Ownership. Management Decision, 52, 378-409. http://dx.doi.org/10.1108/MD-03-2013-0140

[8] Fan, M. and Jiao, L.B. (2011) TMT Characteristics, TMT Heterogeneity and Corporate Performance. Commercial Times, 23, 97-99.

[9] Velinov, E. and Kubicek, A. (2013) The Role of Top Management Teams Heterogeneity in the IPO Process. European Conference on Management, Leadership \& Governance, Academic Conferences International Limited, 325-331.

[10] He, Y.Q. and Yang, W. (2010) A Meta-Analysis on the Relationship between TMT Characteristics and Diversification Strategy. Chinese Journal of Management, 7, 91-97.

[11] Zenger, T.R. and Lawrence, B.S. (1989) Organizational Demography: The Differential Effects of Age and Tenure Distributions on Technical Communication. Academy of Management Journal, 32, 353-376. http://dx.doi.org/10.2307/256366

[12] Boyd, B.K. (2006) CEO Duality and Firm Performance: A Contingency Model. Strategic Management Journal, 16, 301-312.

[13] Finkelstein, S. and D’aveni, R.A. (1994) CEO Duality as a Double-Edged Sword: How Boards of Directors Balance Entrenchment Avoidance and Unity of Command. Academy of Management Journal, 37, 1079-1108. http://dx.doi.org/10.2307/256667

[14] Cho, T.S. and Hambrick, D.C. (2006) Attention as the Mediator between Top Management Team Characteristics and Strategic Change: The Case of Airline Deregulation. Organization Science, 17, 453-469. http://dx.doi.org/10.1287/orsc.1060.0192

[15] Richard, O.C. and Shelor, R.M. (2002) Linking Top Management Team Age Heterogeneity to Firm Performance: Juxtaposing Two Mid-Range Theories. International Journal of Human Resource Management, 13, 958-974. http://dx.doi.org/10.1080/09585190210134309

[16] Pelled, L.H. (1996) Demographic Diversity, Conflict, and Work Group Outcomes: An Intervening Process Theory. Organization Science, 7, 615-631. http://dx.doi.org/10.1287/orsc.7.6.615 